
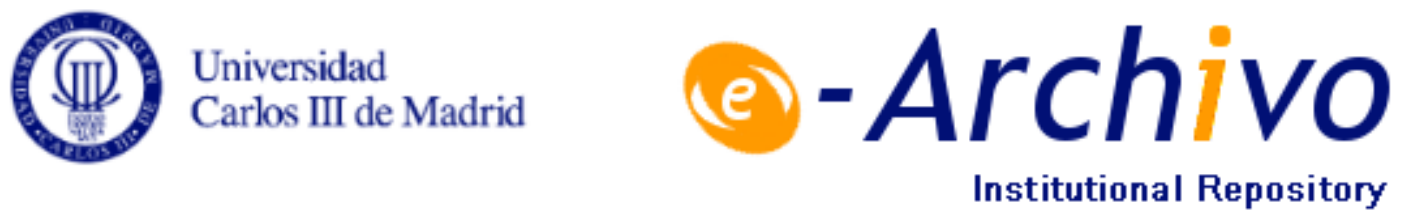

This is a postprint version of the following published document:

J. Zubia, C. Vázquez, J. Mateo.“Optical Fiber Sensor boosts aircraft engine monitoring", in SPIE Newsroom, (2014) 7 June, pp.1-3. Avalilable in http://dx.doi.org/10.1117/2.1201406.005516

(C) 2014 SPIE 


\section{Optical fiber sensor boosts aircraft engine monitoring}

\section{Joseba Zubia, Carmen Vázquez, and Javier Mateo}

A reflective, intensity-modulated optical fiber sensor enables monitoring of tip clearance and tip timing in aircraft engines at low cost and high resolution.

Measuring blade vibrations in aircraft engines is crucial to not only assess turbine operation but also predict blade failures from fatigue. To predict the lifespan of engine blades and to prevent damage that can lead to huge repair costs or even to engine destruction, a low-cost and effective blade vibration system is needed. Fiber-optic sensors (FOS) are well-established technology broadly used to monitor physical parameters in airplanes. For example, FOS have been used to detect impact location and damage, temperature, pressure, strain, and deformation. ${ }^{1}$ Recently, we have demonstrated that FOS are also well suited to measure the blade tip timing (BTT) and tip clearance (TC) in aircraft turbines, ${ }^{2,3}$ two of the main parameters governing the efficiency of a turbine engine. 4

Techniques that measure blade tip timing can provide useful information to monitor the structural health of an engine, whereas tip clearance is related to engine efficiency. Blade vibrations are usually measured with strain gauges. Despite their proven suitability, strain gauges require considerable instrumentation, are restricted to a few blades of the turbine, and require physical contact with the blades, which then disturbs the blade. Other approaches are based on magnets, capacitive sensors, eddy current sensors, discharging probes, require conducting blades, and/or only measure the shortest clearance. ${ }^{5}$ By contrast, FOS are small in size and provide simple, noncontact measurements and instrumentation that are high in sensitivity, resolution, and bandwidth. Furthermore, FOS are robust to electromagnetic interference and can measure every blade.

We used a reflective intensity-modulated FOS to measure both blade tip timing and tip clearance. The main component is a trifurcated optical fiber bundle with three 'legs' on one side and a common leg on the other. The common leg has a central transmitting fiber, which illuminates the blade, and two concentric
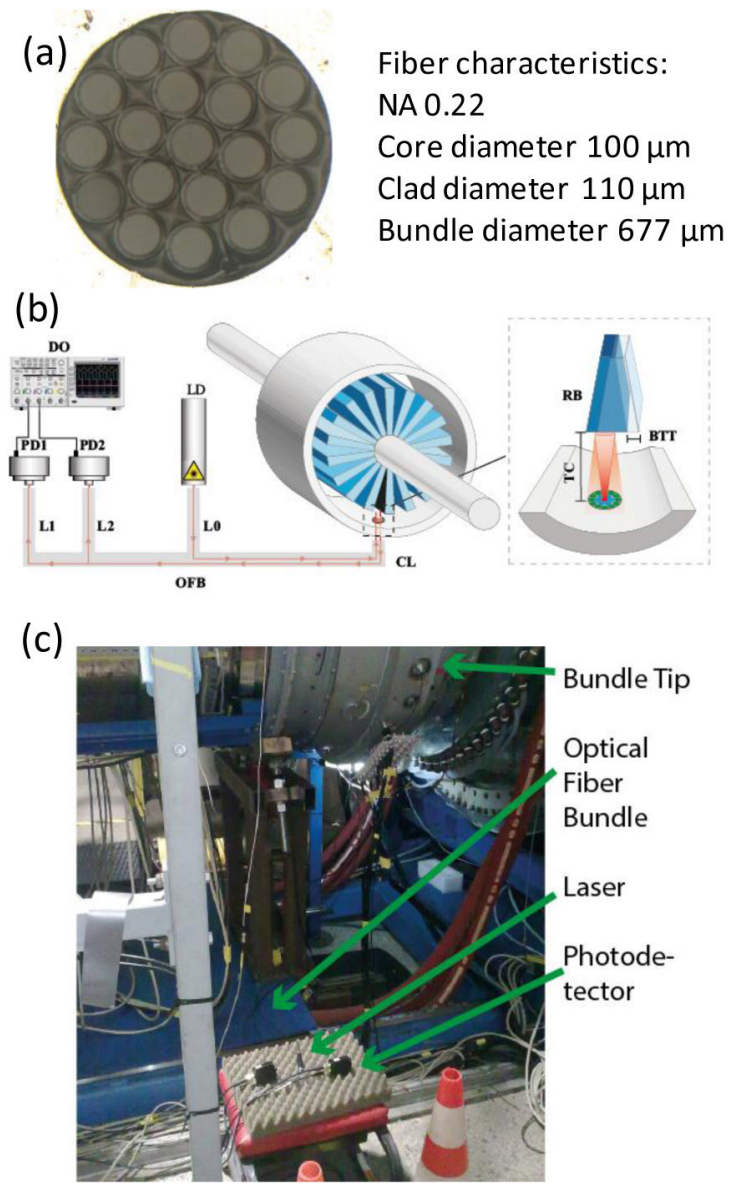

Figure 1. (a) Microscope image of the cross-section of the common leg $(C L)$ of the optical fiber bundle (OFB) of the fiber-optic sensor. (b) Operational principle. (c) Experimental set-up. BTT: Blade tip timing. DO: Digital oscilloscope. L0, L1, L2: Legs of OFB. LD: Laser diode. NA: Numerical aperture. PD1, PD2: Photodetectors. RB: Rotor blade. TC: Tip clearance.

rings of receiving fibers surround the central fiber, which collect the reflected light from the blade. A laser is coupled to the central fiber to transmit the light to the probe end. Two identical

Continued on next page 

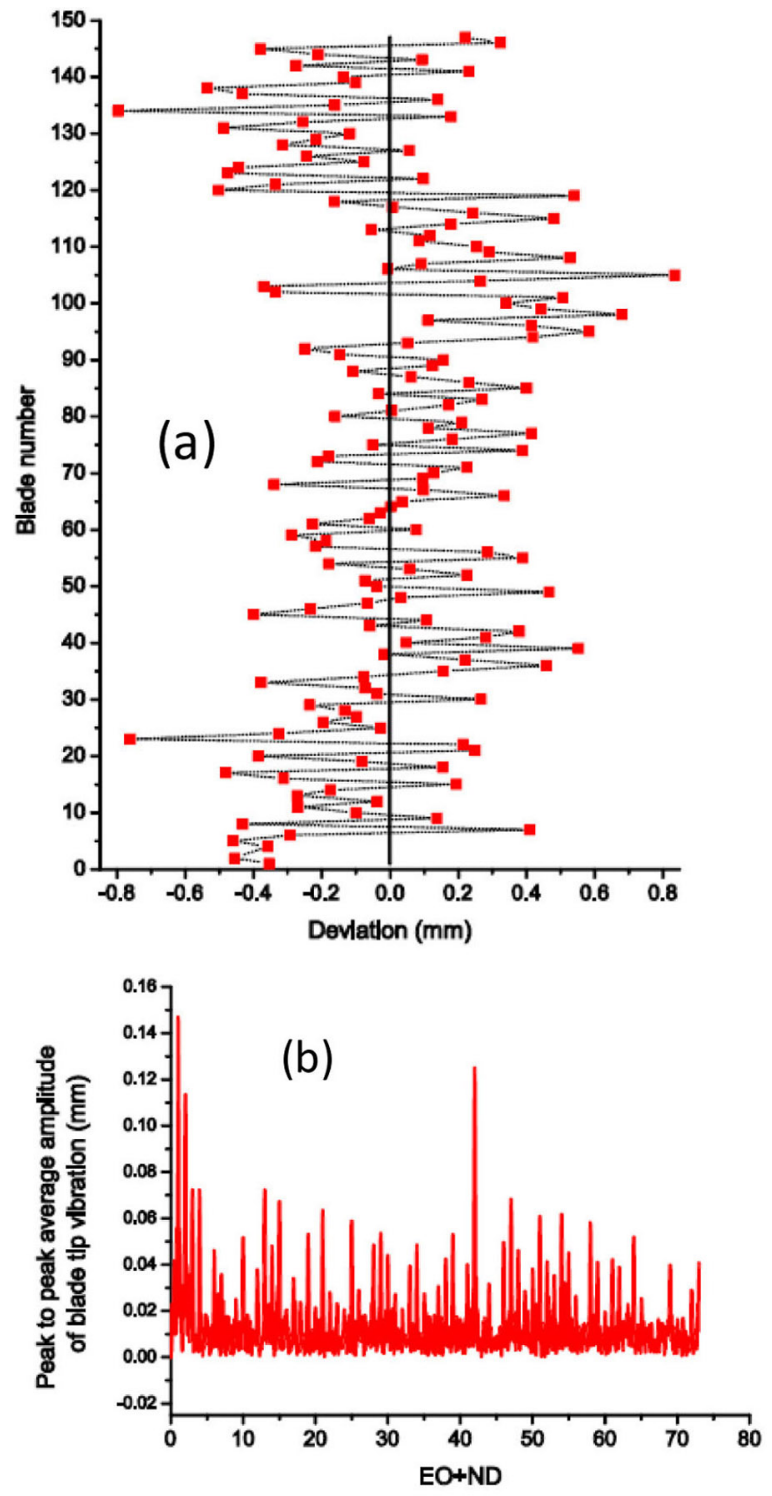

Figure 2. (a) Deviation of each blade from the equilibrium position in a complete revolution. (b) Fourier transform of the deviations. EO: Engine order. ND: Nodal diameter.

photodetectors are connected to the receiving legs to collect the reflected light (see Figure 1).

The TC value is the minimum distance between the tip of a blade and the casing of the engine and is obtained as a function of the quotient of two photodetector voltages. Contrary to the results obtained by other approaches, our sensor has a wide band of frequency response, gives us the distance for each bladerather than for a single blade of contact measurements-with high accuracy (here, $25 \mu \mathrm{m}$ ), and does not require physical contact with the blades. ${ }^{6}$

The BTT technique is based on the measurement of the arrival times (the time taken by the blades to arrive at a fixed position, where the FOS is placed) of all the blades. If the blades vibrate, their arrival times precede or succeed the theoretical nonvibrating arrival times. The difference between these values is converted into blade deflections in the postprocessing of the system. Fast Fourier transform provides the traveling wave spectrum, which is an average value of all the blade vibration amplitudes for each frequency (see Figure 2). This information can then be used to monitor the integrity of the blades against flutter, crack propagation, or foreign-object damage.

With this measurement system, we can simultaneously carry out both BTT and TC measurements with the same probe of a real turbine rig, something other systems cannot do. In addition, the measurement system is a noncontact one, which enables information to be obtained from all the blades with very short instrumentation times and relatively low cost. Next, we hope to characterize the piston seal with three circumferentially equidistributed sensors, placed approximately $5 \mathrm{~mm}$ away from the disk edge. Such a setup should measure TC changes of $\pm 100 \mu \mathrm{m}$ with an accuracy of $1 \mu \mathrm{m}$ in a distance range of $4.5-5.5 \mathrm{~mm}$.

This work has been sponsored by the institutions Ministerio de Economía y Competitividad under project TEC2012-37983-C03; Gobierno Vasco/Eusko Jaurlaritza under projects IT664-13, S-PE13CA004, SPE13UN151, and S-PE12CA001; and by the University of the Basque Country (UPV/EHU) through program UFI11/16.

\section{Author Information}

Joseba Zubia

Basque Country University

Bilbao, Spain

Joseba Zubia received his PhD in physics from the University of the Basque Country in 1993. He is currently a professor of optical communications.

\section{Carmen Vázquez \\ Carlos III University of Madrid \\ Madrid, Spain}

Carmen Vázquez received her $\mathrm{PhD}$ in photonics technologies from Polytechnic University of Madrid. She is currently a professor of optical devices and transmission media. 


\section{Javier Mateo}

University of Zaragoza

Zaragoza, Spain

Javier Mateo received his $\mathrm{PhD}$ in telecommunications engineering in 2000 from the University of Zaragoza. He is currently assistant professor of optical communications and devices and head of the Department of Electronic and Communication Engineering.

\section{References}

1. H. Guo, G. Xiao, N. Mrad, and J. Yao, Fiber optic sensors for structural health monitoring of air platforms, Sensors 11 (4), pp. 3687-3705, 2011. doi:10.3390/s110403687

2. I. García, J. Beloki, J. Zubia, G. Aldabaldetreku, M. A. Illarramendi, and F. Jiménez, An optical fiber bundle sensor for tip clearance and tip timing measurements in a turbine rig, Sensors 13 (6), pp. 7385-7398, 2013. doi:10.3390/s130607385

3. I. Garcia, J. Beloki, J. Zubia, G. Durana, and G. Aldabaldetreku, Turbine-blade tip clearance and tip timing measurements using an optical fiber bundle sensor, Proc. SPIE 8788, p. 87883 H, 2013. doi: $10.1117 / 12.2020540$

4. V. Georgiev, M. Holík, V. Kraus, A. Krutina, Z. Kubín, J. Liška, and M. Poupa, The blade flutter measurement based on the blade tip timing method, Proc. 15th WSEAS Int'l Conf. Systems, pp. 270-275, 2011.

5. M. Zielinski and G. Ziller, Noncontact vibration measurements on compressor rotor blades, Meas. Sci. Technol. 11, p. 847, 2000. doi:10.1088/0957-0233/11/7/301

6. I. García, J. Zubia, A. Berganza, J. Beloki, J. Mateo, and C. Vazquez, Comparison of three different configurations of an optical sensor for tip-clearance measurements in turbines, Proc. SPIE 9157, 2014. 